\title{
Luto antecipatório em pacientes com indicação para o Transplante de Células-Tronco Hematopoéticas
}

\author{
Anticipated grieving in patients requiring \\ hematopoietic stem cell transplantation
}

Érika Arantes de Oliveira Cardoso ${ }^{1}$

Manoel Antônio dos Santos ${ }^{2}$

\footnotetext{
${ }^{1}$ Hospital das Clínicas da Faculdade de Medicina de Ribeirão Preto, Faculdade de Medicina de Ribeirão Preto, Universidade de São Paulo /USP. Av. Bandeirantes s/n, Monte Alegre. 14.040-901 Ribeirão Preto SP. erikaao@ffclrp.usp.br ${ }^{2}$ Departamento de Psicologia da Faculdade de Filosofia, Ciências e Letras de Ribeirão Preto

Universidade de São Paulo.
}

\begin{abstract}
The scope of this study was to understand how the process of anticipated grieving is imbued in patients undergoing Hematopoietic Stem Cell Transplantation (HSCT). A cross-sectional clinical-qualitative study was conducted on a sample of 17 patients, mostly women, married, aged between 20 and 42 years and diagnosed with Chronic Myeloid Leukemia. Data was collected by semi-structured interviews applied individually and subjected to thematic content anal$y$ sis. The results indicate that the loss of health imposes a new challenge in a life history already permeated by great hardships and premature losses. It was found that the expected reactions faced with normal grieving were expressed by the participants and that the most prevalent coping strategy was holding steadfast to their faith. Future plans involved being healed, returning to normality and vocational rehabilitation. The results may help the multidisciplinary teams to understand the emotional implications of the illness/ treatment for implementing both preventive and intervention strategies. The critical aspect is that staff must be attentive as to how to communicate the diagnosis and the possibility of outlining a therapeutic plan, in order to augment the fighting spirit of the patient and strengthen the bond of trust with health professionals.
\end{abstract}

Key words Bone marrow transplant, Stem cells, Grieving, Death
Resumo O objetivo deste estudo foi compreender como o processo de luto antecipatório se instala em pacientes a serem submetidos ao Transplante de Células Tronco-hematopéticas (TCTH). Foi realizado um estudo transversal, na abordagem clínico-qualitativa. Amostra de 17 pacientes, a maioria mulheres casadas, entre 20 e 42 anos de idade e diagnóstico de Leucemia Mieloide Crônica. Dados coletados por um roteiro de entrevista semiestruturada, aplicado individualmente e submetidos à análise de conteúdo temática. Os resultados indicam que a perda da saúde impõe um luto em uma história de vida já permeada por privações e perdas prematuras. Constatou-se que as reações esperadas frente ao luto normal foram expressas pelos participantes e que a estratégia de enfrentamento privilegiada foi o apego à fé. Os planos futuros envolviam alcançar a cura, retorno à normalidade e reinserção profissional. Os resultados podem auxiliar as equipes multiprofissionais a compreenderem as implicações emocionais do adoecimento/tratamento para implantação de estratégias preventivas e interventivas. Como pontos críticos, a equipe deve atentar para a forma de comunicar o diagnóstico e a possibilidade de traçar um plano terapêutico que mantenha vivo o espirito de luta do paciente, reforçando o elo de confiança com os profissionais de saúde.

Palavras-chave Transplante de medula óssea, Células-tronco, Luto, Morte 


\section{Introdução}

O Transplante de Células Tronco-hematopéticas (TCTH) constitui, na atualidade, um dos procedimentos mais arrojados e promissores que surgiram nas últimas décadas para o tratamento de doenças onco-hematológicas, como leucemias e linfomas. Trata-se, contudo, de um procedimento que expõe o paciente a risco significativo de morte, em decorrência dos efeitos colaterais da terapêutica, que exige que o paciente seja submetido à quimioterapia e induz um estado de grave imunossupressão ${ }^{1}$.

Os primeiros conflitos psicológicos vivenciados pelo paciente antecedem o transplante propriamente dito. São os momentos da tomada de consciência do diagnóstico da enfermidade de base. O impacto psicológico do momento do diagnóstico faz com o que o paciente e sua família enfrentem, nessa etapa inicial, a perda da vida "normal", tal como era vivida antes do diagnóstico, sendo obrigados a fazerem o luto pela ruptura da linha de continuidade do cotidiano estruturado anteriormente ao aparecimento da doença grave, além do pesar pela perda de projetos, sonhos e esperança no futuro ${ }^{2}$. Aliado a essas perdas, eles se vêm forçados a encarar a erosão do mito de que as doenças fatais só acontecem com os outros ${ }^{3}$.

Tratando-se da descoberta de uma doença com um prognóstico tão reservado como o câncer, a comunicação do diagnóstico suscita inevitavelmente o temor ante a possibilidade da morte. Passado o choque inicial, tem-se o momento em que se inicia o processo de tomada de consciência das perdas, uma vez que, para muitos pacientes, essa possibilidade transforma-se em certeza e, consequentemente, o diagnóstico convertese em sentença antecipada de morte ${ }^{4,5}$.

As reações emocionais frente a um diagnóstico potencialmente fatal podem ser compreendidas como expressões do luto antecipatório. $\mathrm{O}$ processo de luto tem início já na etapa diagnóstica e se organiza em torno das perdas relacionadas aos aspectos concretos que são mobilizados (perda da saúde, hospitalização, afastamento do cotidiano habitual, alterações da imagem corporal), juntamente com os aspectos subjetivos (perda do senso de controle, segurança e autonomia, déficit de autoestima, angústia) ${ }^{6}$.

Aliado à ruptura biográfica imposta pelo diagnóstico, a situação de tratamento em uma unidade hospitalar de alta complexidade e com elevada taxa de mortalidade, como é o caso do TCTH, contribui para o desencadeamento do processo de luto antecipatório ${ }^{7}$. Em razão das peculiaridades dessa terapêutica, o procedimento passa a ser visto de modo ambivalente, como um tratamento salvador e, ao mesmo tempo, ameaçador ${ }^{8}$. Trata-se, porém, de uma possibilidade de salvação, muitas vezes considerada como o único meio de se alcançar a cura quando se esgotaram os recursos disponíveis ou outras alternativas terapêuticas foram malsucedidas. A esperança de cura impulsiona a decisão pelo TCTH, muitas vezes visto pelo paciente como a última tábua de salvação e a única chance que ainda lhe resta9.

O luto vivenciado antes mesmo de se instalarem as perdas mais substanciais reveste-se das mesmas características e sintomatologia do luto considerado normal: choque, negação, ambivalência, revolta, barganha, depressão, aceitação e adaptação, sendo parte de um processo sistêmico maior ${ }^{10}$. Para a compreensão do luto antecipatório é importante considerar como se deu o estabelecimento de vínculos na vida pregressa do paciente, para que se entenda melhor o processo de rompimento ou esgarçamento dos laços após o adoecimento. Essas vivências anteriores constituem o cenário para o desenrolar do luto antecipatório, que pode se expressar de diversas maneiras, desde a impossibilidade do indivíduo finalizar situações incompletas, até paralisar-se na negação da iminência de terminalidade ${ }^{11}$. A qualidade do vínculo estabelecido primariamente determinará a qualidade dos futuros e as possibilidades de enfrentamento e elaboração por ocasião das perdas enfrentadas durante o ciclo vital ${ }^{12}$.

Nos momentos de luta contra o avanço da enfermidade são acionadas estratégias para o enfrentamento das situações estressantes, que podem ser definidas como esforços de natureza cognitiva, afetiva e comportamental para lidar com exigências, que são avaliadas pelo indivíduo como excedendo seus recursos adaptativos ${ }^{13}$. Tais estratégias de enfrentamento utilizadas pelos pacientes buscam a resolução de problemas ou o manejo das emoções mobilizadas, e representam uma tentativa de obter algum controle diante das situações vivenciadas ${ }^{14}$.

A extensão e a duração das dificuldades resultantes do diagnóstico de câncer hematológico e da necessidade de tratamento podem ser fortemente influenciadas pelas estratégias de enfrentamento utilizadas pelo indivíduo. As situações problemáticas e estressantes, além de resultarem em elevada carga de tensão emocional, podem apresentar a longo prazo efeitos cumulativos, tanto físicos como psicológicos ${ }^{15}$. 
Por outro lado, o luto pode se constituir em um processo de aprendizagem, que permite uma nova concepção de mundo e um reposicionar-se em relação à vida, caso predominem estratégias como a reavaliação positiva das experiências adversas. Desse modo, o luto antecipatório poderia auxiliar o paciente na preparação para o convívio possível com uma enfermidade crônica ou para uma morte iminente ${ }^{16}$.

A literatura disponível nesse campo ainda é incipiente, o que justifica a proposta de estudos que possam contribuir para elucidar o processo do luto antecipatório, de maneira a fornecer subsídios para o planejamento de programas de intervenção e prevenção de complicações psicológicas e psiquiátricas, decorrentes da exposição ao TCTH. Considerando o exposto, o presente estudo tem por objetivo compreender de que modo o processo de luto antecipatório se instala em pacientes diagnosticados com uma doença potencialmente fatal e que serão submetidos ao TCTH.

\section{Percurso Metodológico}

Estudo descritivo e exploratório, de abordagem clínico-qualitativa, com recorte transversal. A pesquisa clínica pode ser definida como aquela que emerge da experiência clínica dos pesquisadores. Esse tipo de delineamento de pesquisa está particularmente interessado em questões inerentes à clínica, devido ao lugar que o pesquisador clínico ocupa no contexto de saúde ${ }^{1718}$. Nessa direção, a experiência pessoal do pesquisador afigura-se como fundamental para a escolha do objeto de pesquisa e para o desenvolvimento do trabalho de investigação ${ }^{19}$.

\section{Participantes}

A amostra foi composta por 17 pacientes, sendo a maioria mulheres (9), casadas (15), com idade entre 20 e 42 anos (sendo 10 com idade superior a 28 anos) e diagnóstico de Leucemia Mieloide Crônica (13). Trata-se de uma amostra de conveniência, obtida consecutivamente da lista de pacientes que se submeteram ao TCTH no primeiro semestre de 2002. Sete pacientes foram a óbito em um período de um ano pós-TCTH.

\section{Instrumento}

Foi utilizado um roteiro de entrevista semiestruturada, delineado especialmente para contem- plar os objetivos do presente estudo. As perguntas visavam à coleta dos dados da história pessoal dos participantes (eventos marcantes vivenciados durante a infância e juventude, namoro/casamento, educação formal, inserção laboral, perdas importantes ocorridas ao longo do ciclo vital), da história familiar (relacionamentos com os pais, irmãos, namorado, cônjuges), da vida atual (saúde, alimentação, sono, atividades de lazer, visando à obtenção de indicadores sugestivos de estresse, ansiedade e depressão), do adoecimento (etapa diagnóstica, acesso a informações sobre a doença), do processo de tomada de decisão acerca da realização do transplante (informações e expectativas em relação ao procedimento), da doação da medula óssea (escolha do doador, informações, e expectativas sobre o processo de doação) e dos projetos futuros.

\section{Cuidados éticos}

Assumiu-se, como princípio básico, o respeito aos voluntários e à instituição hospitalar na qual os dados foram coletados. O projeto foi aprovado pelo Comitê de Ética em Pesquisa da instituição que serviu de cenário ao estudo. Tomou-se o cuidado de esclarecer antecipadamente os objetivos da pesquisa e as condições de sigilo, salientando-se que a pesquisa só seria realizada com aqueles que concordassem com os termos do estudo e assinassem o Termo de Consentimento Livre e Esclarecido para sua realização Dessa maneira, na abordagem dos participantes foi ressaltado o caráter sigiloso e voluntário da participação, explicitando que uma eventual recusa não acarretaria em prejuízos de qualquer tipo no acompanhamento realizado no serviço.

\section{Procedimento}

\section{Coleta de dados}

Os dados foram coletados no momento imediatamente anterior à internação na enfermaria da Unidade de TCTH, em regime de isolamento protetor. As entrevistas foram realizadas em ambiente reservado e gravadas em áudio, mediante a anuência dos participantes. Seguiu-se um roteiro semiestruturado previamente estabelecido, com base na literatura e na experiência clínica e científica dos pesquisadores. O roteiro de entrevista semiestruturada foi aplicado individualmente, em situação face a face. Cada entrevista teve duração de, aproximadamente, uma hora. 


\section{Análise dos dados}

As entrevistas foram posteriormente transcritas na íntegra e literalmente, constituindo o corpus da pesquisa. Foi utilizada a análise de conteúdo temática, visando a identificar concepções, crenças, valores, motivações e atitudes dos participantes do estudo. Primeiramente foi realizada uma leitura flutuante e compreensiva do material, para conhecer as generalidades e particularidades dos relatos dos participantes. Em seguida empreendeu-se uma exploração do material, a partir de leituras sucessivas e exaustivas, tentando ir além das falas explícitas, buscando compreender os conteúdos implícitos e latentes. Por fim, foi realizada uma síntese interpretativa, visando a articular o objetivo do estudo, a fundamentação teórica adotada (teoria do luto antecipatório) e os achados empíricos ${ }^{20}$.

\section{Resultados}

Do corpus analisado emergiram as categorias: "História de vida permeada por perdas precoces", "Luto, adoecimento e tratamento" e "Estratégias de enfrentamento e planos futuros".

\section{História de vida \\ permeada por perdas precoces}

A maioria dos participantes era oriunda de municípios de pequeno porte do interior de diversos estados brasileiros, provinha de famílias desprivilegiadas do ponto de vista socioeconômico e necessitaram trabalhar ainda na infância para contribuírem com o orçamento familiar. As narrativas acerca das trajetórias revelam vidas marcadas não apenas por dificuldades e privações materiais, mas também por perdas precoces de pessoas significativas: morte dos pais na infância, perda de irmãos, filhos e cônjuges.

Minha vida foi muito sofrida. Minha mãe morreu no parto do meu irmão, o que veio depois de mim. Eu era muito nova. O meu pai casou com outra mulher, ela era muito ruim pra nós. (Feminino, 30 anos, casada)

Ela [filha] nasceu de parto prematuro no oitavo mês, ela nasceu com o pulmão... o pulmão dela ainda não estava formadinho, aí ela teve parada cardiorespiratória. (Feminino, 25 anos, casada)

As perdas prematuras de entes queridos ampliaram a vulnerabilidade a que as famílias estavam expostas. Apareceram também dificuldades no relacionamento estabelecido com os pais, sendo que metade dos participantes foi criada por outros familiares, em decorrência de negligência ou abandono sofrido por parte das figuras parentais.

A coisa mais negativa [da infância] foi que minha mãe largou nós... largou nós com meu pai e com a minha avó. É, minha mãe foi embora e levou os dois meninos. (Feminino, 20 anos, casada)

Em decorrência das inúmeras dificuldades vivenciadas no plano de relações familiares, o casamento precoce parece ter sido uma "solução" encontrada pelos participantes, em especial as mulheres, para se evadir de uma situação emocional insustentável. Corroborando esta hipótese, no discurso das mulheres aparece também a gravidez não planejada e a "fuga" de casa com o namorado como meios de deflagar um novo núcleo familiar, com a ascensão a novos papéis e funções familiares.

Eu tinha 14 anos quando comecei a namorare eu fugi com ele. Foi muito rápido, foi uma coisa assim, que na adolescência, né, é assim. Tanta ilusão, né? Mas deu certo, não foi coisa perdida. (Feminino, 26 anos, casada)

\section{Luto, adoecimento e tratamento}

As reações descritas pelos participantes por ocasião do diagnóstico e da tomada de decisão pela realização do TCTH são semelhantes às percebidas em um processo de luto normal, envolvendo emoções e sentimentos intensos, tais como: choque, negação, ambivalência, revolta, barganha, depressão e aceitação.

\section{Choque}

Alguns participantes referiram ausência de sintomatologia, enquanto e outros perceberam sintomas como fraqueza, dores ósseas, vômitos e aparecimento de "caroços" ou "ínguas", que os fizeram buscar avaliação médica.

Em maio de 2005 fui ao médico fazer exame de rotina. Ele me falou que eu tava com um tipo de anemia. Ai ele me passou um remédio e que me deu muita dor no corpo. Eu só piorava e aí ele me encaminhou. (Feminino, 31 anos, casada)

Por residirem em cidades sem recursos de saúde mais sofisticados, tiveram que se deslocar até centros urbanos mais desenvolvidos a fim de obterem o tratamento adequado. Ao tomarem conhecimento do diagnóstico, a reação predominante foi de incredulidade e paralisia:

No começo não vou te dizer que resolvi lutar, assim, de cara. Fiquei paralisado, parecia que a ficha não queria cair. Depois de um tempo é que 
cai na real, me conformei que estava doente e resolvi me tratar. (Masculino, 38 anos, casado)

\section{Negação}

Em função da não correspondência, em muitos casos, entre a expressão fenomenológica da sintomatologia e da gravidade doença, vários participantes não acreditaram na seriedade do seu quadro clínico e esperavam a confirmação de um suposto "erro" da equipe médica.

Não podia ser tão grave. Eu não sentia nada tão sério, só desânimo e fraqueza. Como alguém pode ter uma doença tão grave e sentir tão pouco? Eu ainda esperava que algum exame desmentisse o que os médicos falavam. (Masculino, 22 anos, solteiro)

A negação, nesses casos, parece ter sido um modo de ganhar tempo para absorver o choque do diagnóstico e ajustar-se à nova realidade, que se impunha de maneira inexorável. Em todos os casos esta foi uma reação transitória, que aos poucos foi se dissipando sugerindo a utilização mais exitosa dos recursos adaptativos.

\section{Ambivalência}

A ambivalência afetiva apareceu claramente no desejo de lutar pela sobrevida versus entregar-se à desesperança e desconfiança em relação ao sucesso do TCTH.

Já ouviu o dito: se correr o bicho pega, se ficar o bicho come? É isso, se eu corro e faço o transplante, posso morrer. Se eu fico e não faço, aí morro mesmo. Mas sei que com o transplante ainda tem chance de não dar certo. Então o que fazer? (Masculino, 25 anos, casado)

A perplexidade vivenciada no primeiro estágio do diagnóstico parece se estender após a descoberta da condição paradoxal do tratamento, quando o paciente descobre que sua situação é crítica e que tem pouca margem de liberdade para exercitar sua escolha. Nesse contexto, nenhum caminho the parece seguro, o que requer um esforço no sentido de fazer um balanço dos riscos e benefícios de se submeter à terapêutica do TCTH em vez de persistir no tratamento convencional.

\section{Revolta}

A revolta foi expressa desde um questionamento dirigido a Deus sobre o porquê do adoecimento até uma interpelação dos médicos, pelo modo descuidado como foi comunicado o diagnóstico:
Eu tinha muito medo de questionar por que Deus estava fazendo isso com a gente. Sou crente, sempre tive muita fé... E hoje não questiono porque Ele fez isso, mas me questiono se Ele realmente existe. (Feminino, 26 anos, casada)

A revolta pode se instalar sob a forma de contestação da existência da divindade. Nos casos em que o médico apresentara a previsão do tempo de sobrevida, a relação com a morte era fortalecida e o impacto do diagnóstico se fazia ainda mais devastador.

Eu chorei um monte... fiquei desesperada. Ele me falou que se eu não fizesse o transplante ia viver cinco anos. Eu não queria ouvir isto, né? Nesse momento a minha vida estacionou. Você não tem mais planos, porque teus sonhos acabam. (Feminino, 28 anos, casada)

\section{Barganha}

Passada a revolta, os pacientes reuniram forças para enfrentar a dura realidade do adoecimento e se prepararam para se submeterem ao tratamento. Nesse momento estabeleceram "acordos" com a equipe de saúde, fizeram promessas e tentaram barganhar com Deus, na tentativa de alcançar uma recompensa pelo sofrimento infligido.

Parei de lutar contra. Não foi mais questionar o que me pedem. Vou fazer tudo certinho, seguindo direitinho o que eles falam, o que mandam, não tem como dar errado. Mudei de religião. Agora entendo que essa doença veio com um propósito na minha vida e tenho fé que vou alcançar a graça da cura. (Masculino, 36 anos, casado)

\section{Depressão}

Os pacientes, em geral, já haviam ouvido falar sobre o adoecimento, mas tinham pouca informação sobre sua enfermidade específica. Observou-se que muitas das fantasias em relação à origem da doença traziam conteúdos indicativos de autoculpabilização, o que contribuiu para aumentar o fardo emocional do diagnóstico e reduzir as possibilidades de elaboração psíquica do sofrimento resultante.

Ah, não sei... Se eu disser, alguém pode achar que eu sou louco. Não sei... mas eu penso dessa maneira. Às vezes pode ter sido um descuido quando eu lidava com veneno de lavoura, ou às vezes pode ter sido porque eu mexia com carvão. Eu não me cuidava, agora é só tristeza. (Masculino, 28 anos, casado)

Meu marido me falava: "não chupa limão que afina o sangue". Mas eu insitia em chupar. Ai afi- 
nou mesmo e veio a leucemia. Ele tava certo. Eu fiquei arrasada, triste mesmo, como fiz isso comigo? (Feminino, 42 anos, casada)

\section{Aceitação}

A aceitação da doença veio acompanhada da possibilidade de se submeter a um tratamento que poderia viabilizar a cura. O transplante aparece, em um primeiro momento, como um fator tranquilizador frente ao impacto do diagnóstico: "a doença é grave, mas tem tratamento".

Aí não tinha o que pensar, né? Eu tinha que fazer. Eu tava disposta a aceitar o que o médico dissesse, porque eu já estava ruim mesmo. (Feminino, 29 anos, solteira)

$\mathrm{Na}$ medida em que eram fornecidas informações pela equipe, as preocupações retornavam, em especial no que se refere à necessidade de quimioterapia em altas doses, considerada o grande fator ameaçador do TCTH.

Quando o doutor falou, não aceitei logo de cara. Tive muito medo. Tive medo da quimioterapia, que eu sabia que era muito forte. E depois me falaram do tal do cateter, aí sim é que eu tive mais medo. (Masculino, 38 anos, casado)

A decisão pela realização do TMO foi fundamentada na opinião dos médicos e dos familiares, bem como na esperança de cura. Apesar de terem feito essa opção, alguns pacientes não estavam confiantes no sucesso da terapêutica.

O transplante me preocupa. Porque eu não conheço, não sei o que vou passar. Eu não sei se vai dar, não. (Feminino, 32 anos, casada)

Querer ficar bom, eu quero... mas tem hora que a gente fica meio... não sei se vai dar certo... mas espero que vá correr tudo bem. (Masculino, 42 anos, casado)

\section{Estratégias de enfrentamento e planos futuros}

As estratégias de enfrentamento utilizadas para lidaram com as situações de adoecimento e tratamento foram: o apego à fé, seguido da busca de apoio dos amigos e familiares, a confiança na equipe multiprofissional e, por último, a força de vontade.

Deus dá jeito pra tudo. Eu acho que Deus pode me ajudar. A gente se apega muito a Deus. Nem tudo é que nem a nossa vontade. Meus amigos me ajudam muito. Então eles estão rezando. Eu passei a rezar mais depois que fiquei doente. (Masculino, 42 anos, casado)

Finalmente, em relação aos planos e desejos, em primeiro lugar apareceu o desejo da cura e do retorno a "vida normal". Em termos de planos futuros, a questão da profissão foi dominante na maioria dos relatos, aparecendo o desejo de retomar ou modificar a ocupação que exerciam anteriormente, além da vontade de voltar a estudar e de criar os filhos.

\section{Discussão}

Os resultados evidenciam que, antecedendo ao adoecimento e tratamento, uma questão preliminar aparece com muita força: a história de vida dos pacientes, de onde vieram, quais as suas marcas, que padrão de vida levavam e o que perderam ou foi substancialmente modificado em decorrência das vicissitudes da doença e do transplante.

A análise dos dados das entrevistas permitiu constatar que a vida dos participantes foi marcada por privação material, acarretando a necessidade precoce de inserção no mundo do trabalho ainda na infância, além de dificuldades no plano dos relacionamentos familiares. Constatou-se também um histórico de perdas prematuras de pessoas muito próximas e significativas, tais como: pai, marido, filhos.

A compreensão das histórias de vida, vínculos afetivos pregressos e reações aos rompimentos precoces desses vínculos são dados importantes para a compreensão da forma como ocorreu o luto antecipatório desses participantes ${ }^{11}$. Esse seria o "pano de fundo" para a compreensão do momento delicado da vida dos pacientes, no qual a perda da saúde representa uma perda a mais na vida de quem sempre teve tão pouco. Nesse sentido, estar exposto a uma doença grave adquire um significado muito específico, que vai além da possibilidade de perda do bem maior, que é a própria vida.

Fica evidente o movimento inicial de choque e negação da áspera realidade do diagnóstico, seguido por reações de ambivalência, revolta, indecisão, barganha, depressão e, posteriormente, aceitação. Essas reações, esperados no luto propriamente dito, são comuns nos casos de luto antecipatório $^{10}$.

O choque e a negação do diagnóstico vêm acompanhados pela necessidade de compreensão da origem do adoecimento. Não dispondo de uma explicação científica que desvele sua etiologia, os entrevistados valorizam o sofrimento psíquico, as dificuldades financeiras e o excesso de trabalho como prováveis mecanismos desencadeadores da doença. Tais explicações propostas para o adoecimento figuram também no dis- 
curso de outros pacientes com câncer investigados no contexto brasileiro ${ }^{21}$. A construção de representações sobre a origem do problema pode revelar uma busca de significados para o adoecer que estejam inscritos na própria cotidianidade. Esse fenômeno pode ser interpretado como um esforço para dotar de sentido e tornar familiar (e, portanto, mais próximo e conhecido) o caráter desconhecido, enigmático e profundamente desconcertante da enfermidade.

Diante do quadro de incertezas e indefinições geradas pela experiência vivida, torna-se compreensível que o impacto do diagnóstico seja desencadeador de vivências de revolta e desesperança, bem como se entende a necessidade dos pacientes de se sentirem acolhidos e amparados no momento em que se sentem devastados e vulneráveis. A comunicação do diagnóstico do câncer, na perspectiva do paciente, implica muito mais do que receber passivamente um comunicado impactante, pois se trata, para ele, de um marco divisor do tempo entre um antes e um depois dessa comunicação. Nesse instante, mais do que uma profusão de informações acerca do diagnóstico e do prognóstico, o paciente necessita do conforto oferecido pelos profissionais de saúde e pela possibilidade concreta de um tratamento que lhe acene com alguma esperança e consolo ${ }^{22}$.

Para o paciente, o que há de pior na comunicação do diagnóstico não é tanto o conteúdo da má notícia, mas a expectativa do que vai acontecer depois ${ }^{21}$. Essa ênfase na importância do prognóstico auxilia na compreensão da insatisfação, manifestada pela metade dos pacientes sobreviventes incluídos no presente estudo, quanto à forma como foi comunicado o diagnóstico, sendo que a queixa maior refere-se à estimativa oferecida em relação ao tempo de sobrevida, em geral de cinco ou seis anos. Esse tipo de explicação médica impessoal, pautada na comunicação de taxas, previsões e estatísticas de sobrevivência, não contribui para amenizar o impacto causado pelo contato com a possibilidade da finitude; pelo contrário, faz com que muitas vezes o paciente perca a confiança na equipe multiprofissional que $\mathrm{o}$ atendeu ${ }^{23}$.

Obviamente, a tarefa de se dar uma má notícia não é nada simples ${ }^{24,25}$. O profissional encarregado deve assumir uma postura ativa, no sentindo de comunicar e transmitir informações e, ao mesmo tempo, deve adotar uma atitude empática, para acolher o sofrimento do paciente e manter viva sua esperança de recuperação ${ }^{26,27}$. Tal postura empática e, em especial, a percepção, por parte do paciente, do acolhimento proporcionado pelo profissional de saúde, pode não so- mente atenuar o impacto do diagnóstico, como também auxiliar no posterior ajustamento frente à situação de tratamento e recuperação do paciente.

Em uma tentativa de amenizar o impacto dos eventos estressores, associados ao diagnóstico de uma enfermidade grave e aos percalços de seu tratamento, os pacientes fazem uso de algumas estratégias de enfrentamento ${ }^{21}$. No presente estudo, constatou-se que as formas eleitas para enfrentarem a da situação do adoecimento e do tratamento compreenderam: o fortalecimento da fé e do vínculo de confiança com os profissionais da equipe de saúde, o apoio familiar e a "força de vontade".

Sem dúvida, a estratégia mais utilizada pelos participantes foi a fé. A utilização da fé como principal recurso de enfrentamento também foi encontrada em diversos estudos que abordaram a reação de pacientes frente à descoberta do cân$\operatorname{cer}^{21,23,28}$. Em estudo realizado no mesmo cenário hospitalar da presente investigação, a partir dos discursos das crianças e adolescentes que sobreviveram ao TCTH, foi constatado que, para esses pacientes, ter fé e acreditar em Deus foram recursos imprescindíveis para o enfrentamento das adversidades da situação de tratamento ${ }^{14}$.

Esse apego à fé pode ser compreendido como a busca do sagrado, em resposta às questões existenciais suscitadas frente à vivência da finitude desencadeada pelo adoecimento e pela exposição aos riscos inerentes ao tratamento ${ }^{29}$. A fé, nesses casos, teria o poder de proporcionar alívio, como um bálsamo capaz de cicatrizar as dores provocadas pelo desatino da existência. Desse modo, o apego à fé aparece como recurso que poderia vir a dar algum sentido para a experiência desestabilizadora do adoecimento e do tratamento, o que auxiliaria no processo de enfrentamento do diagnóstico e do $\mathrm{TCTH}^{23,30}$.

Um dado importante a ser considerado quando se menciona a condição psicológica dos pacientes submetidos ao transplante é a modificação que eles implementam na forma de viver a vida, diferentemente do desejo de resgate da "normalidade" perdida. Esse desejo de reversibilidade à situação anterior ao adoecimento nunca é satisfeito, uma vez que a vida desconhece a reversibilida$\mathrm{de}^{31}$. Além disso, desistir da ambição de lograr a restituição ao estado anterior ao adoecimento pode vir a ter um efeito libertador, permitindo a criação e instituição de novas normas, de uma forma de viver renovada. O que aparece depois do adoecimento é um ser modificado, que mesmo quando apto a alcançar o mesmo desempenho de que era capaz antes da enfermidade, agora 
o faz percorrendo caminhos diferentes. Ao doente é exigida a criação de novas normas que permitam a continuidade de sua vida, porém de uma que não continua idêntica a de antes ${ }^{32}$.

Chama a atenção a frequência com que aparece o desejo de reorganização da vida profissional. Tal desejo pode ser tanto desencadeador de ansiedade, quanto funcionar como incentivo para o enfrentamento da situação de adoecimento e do tratamento ${ }^{23}$. Por isso, é de fundamental importância o trabalho de reabilitação ocupacional para melhorar a qualidade de vida desses pacientes ${ }^{33}$.

Esses desejos e planos futuros, por si só, representam um indício de qualidade de sobrevivência, uma vez que esses pacientes vão além da condição estagnada de sobreviventes ao câncer. Eles buscam não permanecer aprisionados no presente opressivo, mas se permitindo projetar no futuro, elaborando ou reelaborando seu projeto de vida ${ }^{34}$. Assim, do ponto de vista do imaginário, o futuro é investido não mais apenas com temores e apreensões, mas como pleno de potencialidades criativas e restauradoras.

\section{Considerações Finais}

Pode-se concluir que o diagnóstico do um câncer hematológico, apesar dos conhecidos avanços da medicina, ainda continua sendo encarado como sinônimo de sentença de morte para o paciente, desencadeando a vivência do luto antecipatório ${ }^{20}$.

Após conhecer o diagnóstico inicial, o paciente e seus familiares tentam compreender e dar sentido à doença e ao tratamento, sendo frequentes os sentimentos de medo e incertezas quanto ao povir ${ }^{13}$. Nesse cenário delicado, é de fundamental importância oferecer atenção às necessidades emocionais do paciente e do familiar ${ }^{34}$.

Uma das formas de atenuar tal sofrimento é estabelecer um vínculo baseado na empatia e na capacidade de transmitir esperança para o paciente na etapa do diagnóstico, sendo muito importante nesse momento delinear um prognóstico, que pode ter implicações na forma de enfrentamento da doença e do tratamento ${ }^{22.23}$.

Considera-se que o prognóstico oferecido deve ser realista e consistente com o conhecimento cientifico que se dispõe no momento, contudo, é preciso levar em consideração o uso que o paciente poderá fazer de tais informações e seu impacto potencial sobre as suas expectativas de cura. É recomendável que os esclarecimentos sejam pautados em uma linguagem clara, objetiva e condizente com a capacidade cognitiva e emocional de cada paciente, que vai assimilar as informações e prescrições médicas de acordo com suas possibilidades e limites, "filtrando" o que lhe parecer mais significativo e que faça sentido dentro de seu contexto de vida.

\section{Colaboradores}

Oliveira EAC foi responsável pela concepção e condução do projeto de pesquisa, coleta, análise e interpretação dos dados, e elaboração da versão inicial do texto. MA Santos foi responsável pelo delineamento metodológico do estudo, análise e interpretação dos dados, elaboração da redação final do texto e aprovação da versão final do artigo.

\section{Agradecimentos}

Estudo financiado pela Fundação de Amparo à Pesquisa do Estado de São Paulo (FAPESP), e Conselho Nacional de Desenvolvimento Científico e Tecnológico (CNPq), Bolsa de Produtividade em Pesquisa. 


\section{Referências}

1. Matias AB, Oliveira-Cardoso EA, Mastropietro AP, Voltarelli JC, Santos MA. Qualidade de vida e transplante de células-tronco hematopoéticas alogênico: um estudo longitudinal. Estud Psicol (PUCCAMP) 2011; 28(2):187-197.

2. Rivera LM. Blood cell transplantation: its impact on one family. Semin. Oncol. Nurs 1997; 13(3):194-199.

3. Rolland JS. Ajudando as famílias com perdas antecipadas. In: Walsh F, Mc Goldrick M, organizadores. Morte na família: sobrevivendo às perdas. Porto Alegre: ArtMed; 1998. p. 166-186.

4. Santos MA, Silva AFS, Oliveira-Cardoso EA. Impact of autologous hematopoietic stem cell transplantation on quality of life of type 1 diabetes mellitus patients. Psicol Refl Crít 2011; 24(1):264-271.

5. Oliveira-Cardoso EA, Mastropietro AP, Santos MA, Voltarelli JC. Apoio psicológico na terminalidade: ensinamentos para a vida. Psicol Estud (Maringá) 2010; 15(1):235-244.

6. Fonseca, J. P. Luto antecipatório. Campinas (SP): Livro Pleno; 2004.

7. Flach K, Lobo BOM, Potter JR, Lima NS. O luto antecipatório na unidade de terapia intensiva pediátrica: relato de experiência. Rev SBPH 2012; 15(1):83-100.

8. Copper MC, Powell G. Technology and care in a bone marrow transplantation unit: creating and assuaging vulnerability. Holist Nurs Pract 1998; 12(4):57-62.

9. Prows C, McCain G. Parental consent for bone marrow transplantation in the case of genetic disorders. J. Soc Pediatric Nurses 1997; 2(1):9-18.

10. Fonseca JP. Luto antecipatório: as experiências familiares diante de uma morte anunciada [dissertação]. São Paulo: Pontifica Universidade Católica; 2001.

11. Fonseca JP, Fonseca MI. Luto antecipatório. In: Franco MHP, organizadora. Estudos avançados sobre o luto. Campinas: Livro Pleno; 2002. p. 69-94.

12. Lazarus R, Folkman S. Stress, appraisal, and coping. New York: Springer Publishing; 1984.

13. Anders JC. O transplante de medula óssea e suas repercussões na qualidade de vida de crianças e adolescentes que o vivenciaram [tese]. Ribeirão Preto (SP): Universidade de São Paulo; 2004.

14. Gimenes MGG, Fávero ML, Silva EMB. Terminalidade e enfrentamento: a relação entre emoção, cognição e qualidade de vida de mulheres mastectomizadas em fase terminal. In: Gimenes MGG, organizadora. A mulher e o câncer. Campinas: Editora Psy; 1997. p. 225-258.

15. Parkes CM. Luto: estudo sobre a perda na vida adulta. São Paulo: Summus; 1998.

16. Brewer J, Hunter A. Multimethod research: a syntesis of styles. Thousand Oaks: Sage Newbury Park; 1989.

17. Miller WL, Crabtree BF. Primary care research: a multimethod tipology and qualitative roadmape. In: Crabtree BF, Miller WL, editors. Doing qualitative research. $2^{\text {nd }}$ Edition. Thousand Oaks: Sage Thousand Oaks; 1999.

18. Hulley SB, Cummings SR, Browner WS, Grady D, Hearst N, Newman TB. Delineando a pesquisa clínica: uma abordagem epidemiológica. 2a Edição. Porto Alegre (RS): Artmed; 2003.
19. Minayo MCZ, organizadora. Pesquisa social: teoria, método e criatividade. 29a Edição. Petrópolis (RJ): Vozes; 2010.

20. Cruz MRS. Pacientes oncológicos: estudo da percepção das modificações de seu papel no grupo familiar. In: Turato ER, organizador. Psicologia da Saúde: estudos clínicos-qualitativos. Taubaté (SP): Cabral Editora e Livraria Universitária; 2003. p. 121-136.

21. Kovács MJ. Avaliação da qualidade de vida em pacientes oncológicos em estado avançado da doença. In: Carvalho MM, organizadora. Psico-oncologia no Brasil: resgatando o viver. São Paulo: Summus; 1998. p. 186-231.

22. Salander R. Bad news from the patient's perspective: an analysis of the written narratives of newly diagnosed cancer patients. Soc Sci Med 2002; 55(1): 721-732.

23. Rezende VL, organizadora. Reflexões sobre a vida e a morte: abordagem interdisciplinar do paciente terminal. Campinas (SP): Editora da UNICAMP; 2000.

24. Friedrichsen MJ, Strang PM. Doctors' strategies when breaking bad news to terminally ill patients. $J$ Palliative Med 2003; 6(4):565-574.

25. Parker PA, Baille FW, Moor C, Lensi R, Kudelka AP, Cohen L. Breaking bad news about cancer: patient's preferences for communication. J Clin Oncol 2001; 19(7):2049-2056.

26. Schofield PE, Butow PN, Thompson JF, Tattersall MH, Beeney LJ, Dunn SM. Psychological responses of patients receiving a diagnosis of cancer. Ann Oncol 2003; 14(1):48-56.

27. Mager WM, Andryskowski MA. Communication in the cancer "bad news" consultation: patient perceptions and psychological adjustment. Psychooncology 2002; 11(1):35-46.

28. Angerami-Camon VA, organizador. Novos rumos na psicologia da saúde. São Paulo: Pioneira Thomson Learning; 2002.

29. Barros MCM. Aspectos psicológicos relacionados à experiência do transplante de medula óssea. $R S B C$ 2002; 5(9):26-30.

30. Canguillem G. O normal e o patológico. 3a Edição. Rio de Janeiro: Forense-Universitária; 1990.

31. Serpa Júnior OD. Indivíduo, organismo e doença: a atualidade de "O normal e o patológico" de Georges Canguilhen. [acessado 2013 mar 23]. Disponível em: http://www.puc-rio.br/sobrepuc/depto/psicologia/ Octavio.html.

32. Mastropietro AP, Oliveira-Cardoso EA, Santos MA. Vida ocupacional de pacientes sobreviventes ao transplante de medula óssea: estudo exploratório. RBOP 2011; 12(1):241-252.

33. Araújo TCCF, Arraes AR A sobrevivência em oncologia: uma vivência paradoxal. RPCP 1998; 18(2):2-9.

34. Fratezi FR, Gutierrez BAO. Cuidador familiar do idoso em cuidados paliativos: o processo de morrer no domicílio. Cien. Saude Colet 2011; 16(7): 32413248.

Artigo apresentado em 30/04/2013

Aprovado em 22/05/2013

Versão final apresentada em 04/06/2013 